\title{
Stability and Phase Space Analysis of Fluidized-Dense Phase Pneumatic Transport System
}

\author{
Baldeep Kaur ${ }^{*}$, Anu Mittal ${ }^{2}$, Soumendu Jana ${ }^{1}$, S.S. Mallick² and Peter Wypych ${ }^{3}$ \\ ${ }^{1}$ School of Physics and Materials Science, Thapar University, Patiala, Punjab-147004, India \\ ${ }^{2}$ Department of Mechanical Engineering, Thapar University, Patiala, Punjab-147004, India \\ ${ }^{3}$ Faculty of Engineering and Information Sciences, University of Wollongong, NSW-2522, \\ Australia
}

*Corresponding author. Email address: sohalbaldeep@ gmail.com

Telephone number: +91-175-2393080

\begin{abstract}
Fluidized dense-phase pneumatic conveying of powders is gaining popularity in several industries, such as power, chemical, cement, refinery, alumina, pharmaceutical, limestone etc., because of reduced gas flow rate and power consumption, decreased conveying velocities, improved product quality control, reduced pipeline sizing and wear rate, increased workplace safety etc. However, understanding the fundamental transport mechanism of fluidized dense-phase transport has only made limited progress because of the highly concentrated and turbulent nature of the gas-solids mixture. In the present work, pneumatic conveying trials were conducted with power plant fly ash (median particle diameter: $30 \mu \mathrm{m}$; particle density: $2300 \mathrm{~kg} / \mathrm{m}^{3}$; loose-poured bulk density: 700 $\mathrm{kg} / \mathrm{m}^{3}$ ) through $69 \mathrm{~mm}$ I.D. x $168 \mathrm{~m}$ long pipeline. The mass momentum and energy balance of the system lead to the formulation of governing equations of flow for the dense-phase pneumatic conveying, which were solved using Runge-Kutta-Fehlberg (RKF45) method for different mass flow rates of fly ash and air. The stability of the system has been established corresponding to the four critical conveying parameters: pressure drop, particle and solid velocities and solid volume fraction. The linear stability analysis for the system has been established using Lyapunov's
\end{abstract}


exponent method along with Hurwitz criteria. This results of stability analysis indicate a possible change in the characteristics of dunes and transport mechanisms in the direction of flow. The system experiences drop in pressure and solids volume fraction with increasing air and solids velocity. The study has been conducted at different combinations of mass flow rates of air and solids. Two- and three-dimensional phase space portraits of critical system parameters under study (pressure drop, particle velocity, gas velocity, solids volume fraction and solids friction factor) show the bistable and multi-stable operating regions for the system.

Keywords: pneumatic conveying, dense-phase, fine powders, linear stability analysis, solids friction, phase space and bistability 


\section{Introduction}

Fluidized dense-phase pneumatic transport is the preferred method for conveying fine powders in several industries, such as coal fired thermal power plants, chemical, pharmaceutical, petrochemical plants, cement, food industries, etc. over the conventional dilute-phase mode due to the reasons of high solids to gas mass ratio, low gas flow requirement (i.e. smaller compressor and savings in operating power requirement), smaller size of pipes and fittings, reduced conveying velocity resulting in lowering of wear rate of pipelines and bends, decreased rate of product attrition, reduced size of solids-gas separation unit etc. [1, 2]. Typically fine powders (Geldart Group A material) that have good air retention capabilities, such as fly ash, cement, pulverized coal etc., are able to support fluidized dense-phase mode of conveying $[2,3]$. In this regime of transport, the gas velocities are kept lower than the saltation velocities of particles, so that the conveying can take place in a non-suspension mode $[1,2]$. In spite of having several merits, fundamentally understanding the flow mechanisms and reliably designing fluidized dense-phase systems have made only limited progress so far. This is because in fluidized dense-phase flows, the aerated fine powders form dunes and move along the bottom of pipe [2]. Such turbulent natured dunes are very difficult to be fundamentally modelled due to the complexities to link the particle and bulk properties during actual flow conditions. Comparatively, relatively more success based on fundamental modelling methods using powder mechanics have been developed for low-velocity slug-flow of granular products [4] or the dilute-phase flow of bulk solids flow mechanics can be considered to be applicable with a fair accuracy [5]. Because of the limited progress achieved so far in fundamentally understanding the transport mechanisms of fluidized bulk solids, empirical power function based models have been popularly developed over the years by several 
investigators for important design parameters, such as minimum transport (to predict flow blockage condition) and solids friction factor (to determine pressure drop in pipes) [2, 6-10]. These models [2, 6-10] have shown good predictions when applied to researchers' own data, but previous investigation [2] has demonstrated that the empirical models can unexpectedly result in significant inaccuracy under scale-up conditions of pipeline length and diameter. The existing models are based on dimensionless numbers, such as particle and gas based Froude number, volumetric loading ratio etc. [2, 6-10], but these have not taken into consideration the important flow attributes, such as, the flow characteristics of the dunes. The dunes are formed when the fluidized powders are pushed out of blow tanks with the help of a combination of top, fluidization and conveying air (depending on blow tank design and operation) [1]. Most of the existing models for solids friction factor or minimum transport criteria include mass or volumetric flow ratios, but these do not consider the nature of the dunes. In the experience of the authors, the nature of the dunes is a critically important parameter that strongly influences the pressure drop in the pipeline; it has been experimentally observed that there could be considerably different pressure drop due to the varying nature of the moving dunes (dunes filling up the pipe cross section) even for the similar mass flow rates of solids and air. Hence, in order to model fluidized dense-phase flow reliably and from a more fundamental standpoint, it is necessary to analyze the important dune characteristics. Fundamentally and practically, it is of considerable importance to learn whether the dunes change their characteristics along the length of flow. This can happen in a long pipeline, such as in the case of fluidized dense-phase pneumatic conveying of fly ash in power stations (the distance could be as long as $1 \mathrm{~km}$ ). It is intuitive to think that if the nature of the dunes are changing along the length of the flow (due to increasing flow velocity caused by gas expanse in the direction of flow and due to the impact of the dunes on the wall of pipes and bends), the pressure drop per 
unit length of pipes should vary from the feed point to the exit of pipeline. Therefore, stability of the dunes are to be examined along the length of flow. Stability analysis is a mathematical technique to determine the behavior of the system w.r.t to time/space and this can be extended to pneumatic transport [1]. Number of methods for stability analysis exist in literature, such as Lyapunov exponent's method [11], linear stability analysis [12], perturbation method [13] and von Neumann Stability analysis [14]. There have been some cases where the researchers have used stability analysis to study the particle-fluid systems, such as Chen et al. [15] to Fullmer and Hrenya [21]. These work were carried out either with granular products or coarser particles in standpipes or with fluidized beds and very little research has been conducted in the area of stability analysis for fluidized dense-phase pneumatic conveying of fine powders through pipes. This paper investigates into the stability of moving dunes of fine aerated powders through pipelines. An unstable dune would indicate change in flow mechanism along the length of pipe and the need to incorporate such change in flow condition in the model describing the transport mechanism.

\section{Experimental work}

Power station fly ash was conveyed from fluidized dense- to dilute-phase in 69 mm I.D. x $168 \mathrm{~m}$ long pipeline at the Bulk Materials Handling Laboratory of University of Wollongong, Australia. The fly ash was conveyed with different air and solids mass flow rates. Physical properties of the fly ash and pipeline conditions are given in Table 1. Particle size distributions were measured using laser diffraction method. 
Table 1: Physical properties of the fly ash conveyed.

\begin{tabular}{|c|c|c|c|c|c|c|c|}
\hline $\begin{array}{c}\text { Fly ash } \\
\text { no. }\end{array}$ & $\begin{array}{c}\mathbf{d}_{10} \\
(\boldsymbol{\mu m})\end{array}$ & $\begin{array}{c}\mathbf{d}_{50} \\
(\boldsymbol{\mu m})\end{array}$ & $\begin{array}{c}\mathbf{d} \mathbf{9 0} \\
(\boldsymbol{\mu m})\end{array}$ & $\begin{array}{c}\mathbf{\rho}_{\mathrm{s}} \\
\left(\mathbf{k g} / \mathbf{m}^{3}\right)\end{array}$ & $\begin{array}{c}\mathbf{\rho b}^{3} \\
\left(\mathbf{k g} / \mathbf{m}^{3}\right)\end{array}$ & $\begin{array}{c}\mathbf{D} \\
(\mathbf{m m})\end{array}$ & $\begin{array}{c}\mathbf{L} \\
(\mathbf{m})\end{array}$ \\
\hline 1 & 5 & 30 & 145 & 2300 & 700 & 69 & 168 \\
\hline
\end{tabular}

Schematic diagram of the 69 mm I.D. x 168 m long pipeline is shown in Figure 1.

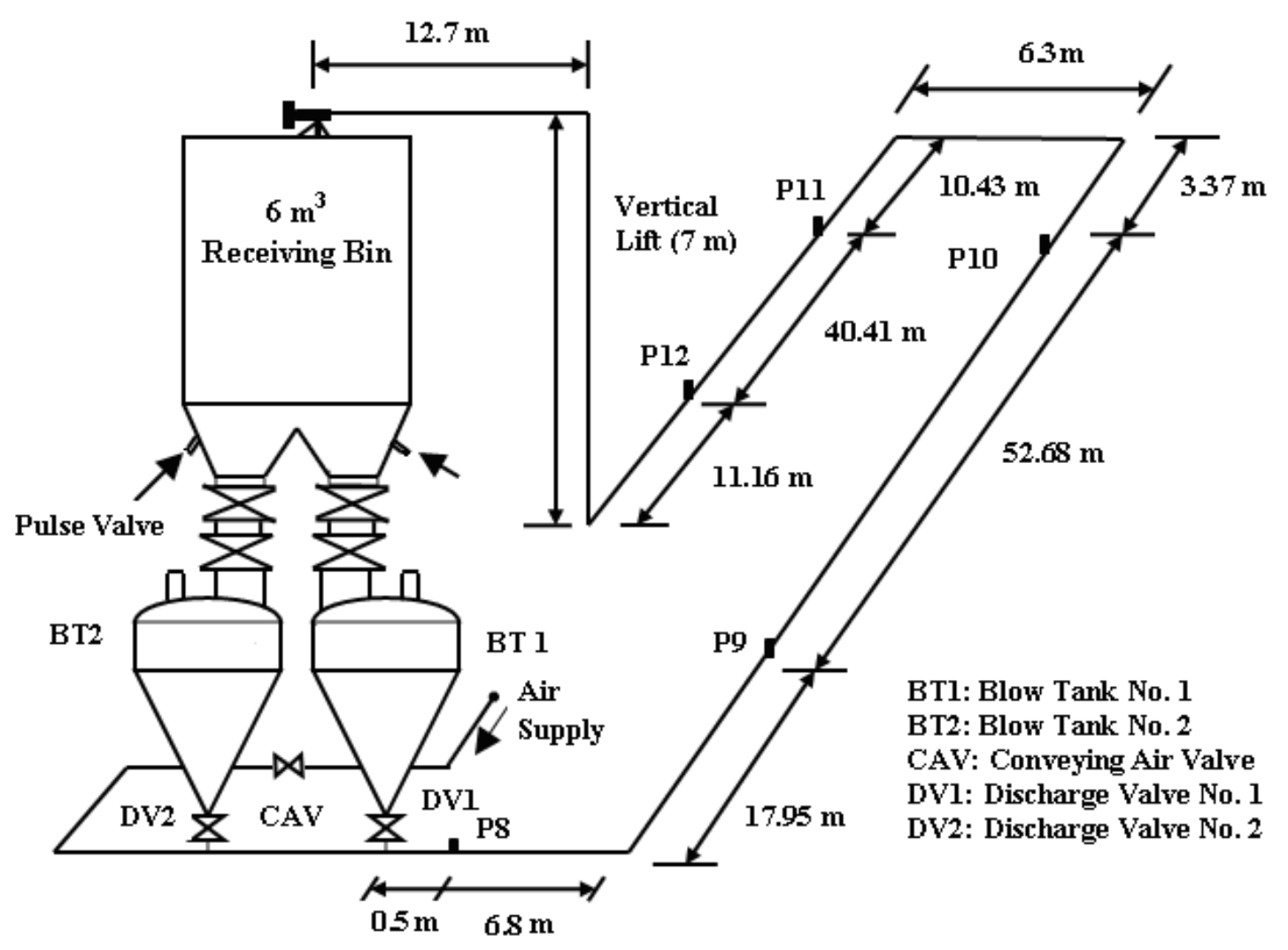

Figure 1: Layout of the $69 \mathrm{~mm}$ I.D. x $168 \mathrm{~m}$ test rig (for fly ash). 
The test facility comprised of:

- Tandem $0.425 \mathrm{~m}^{3}$ bottom-discharge blow tank feeding system;

- $69 \mathrm{~mm}$ I.D. $\times 168 \mathrm{~m}$ long mild steel pipeline, including $6.5 \mathrm{~m}$ vertical lift, five $1 \mathrm{~m}$ radius $90^{\circ}$ bends and $150 \mathrm{~mm}$ N.B. tee-bend connecting the end of the pipeline to the feed bin;

- Static pressure measurements at two straight pipe tapping locations: P9-P10 (52.68 m apart) and P11-P12 (40.41 $\mathrm{m}$ apart), the tapping locations were selected such that they are out of the influence of any bend effect. Total pipeline pressure drop was measured using the P8 transducer. The static pressure transducers had the following specification: manufacturer: Endress and Hauser, model: Cerabar PMC133, pressure range: 0-6 and 0-2 bar-g, maximum pressure: 40 bar (absolute), current signal: 4 to $20 \mathrm{~mA}$;

- Ingersoll Rand diesel-powered Model P375-WP, $10.6 \mathrm{~m}^{3} / \mathrm{min}$ free air delivery screw compressor was used to supply compressed air at a maximum pressure of approximately $800 \mathrm{kPa}-\mathrm{g}$;

- $6 \mathrm{~m}^{3}$ receiving bin with insertable pulse-jet dust filter;

- All necessary instrumentation (e.g. pressure transmitters, load cells on feed bin and receiving bin, annubar with DP meter);

- Data acquisition unit for data recording and analysis.

Using steady state straight-pipe pressure drop data for a range of solids and air flow rates through P9-P10 and P11-P12 tapping points for the $69 \mathrm{~mm}$ I.D. $\times 168 \mathrm{~m}$ long pipe, the following straightpipe pneumatic conveying characteristics (PCC) have been obtained (Figures 2 and 3). Constant mean Froude number lines have been shown. 


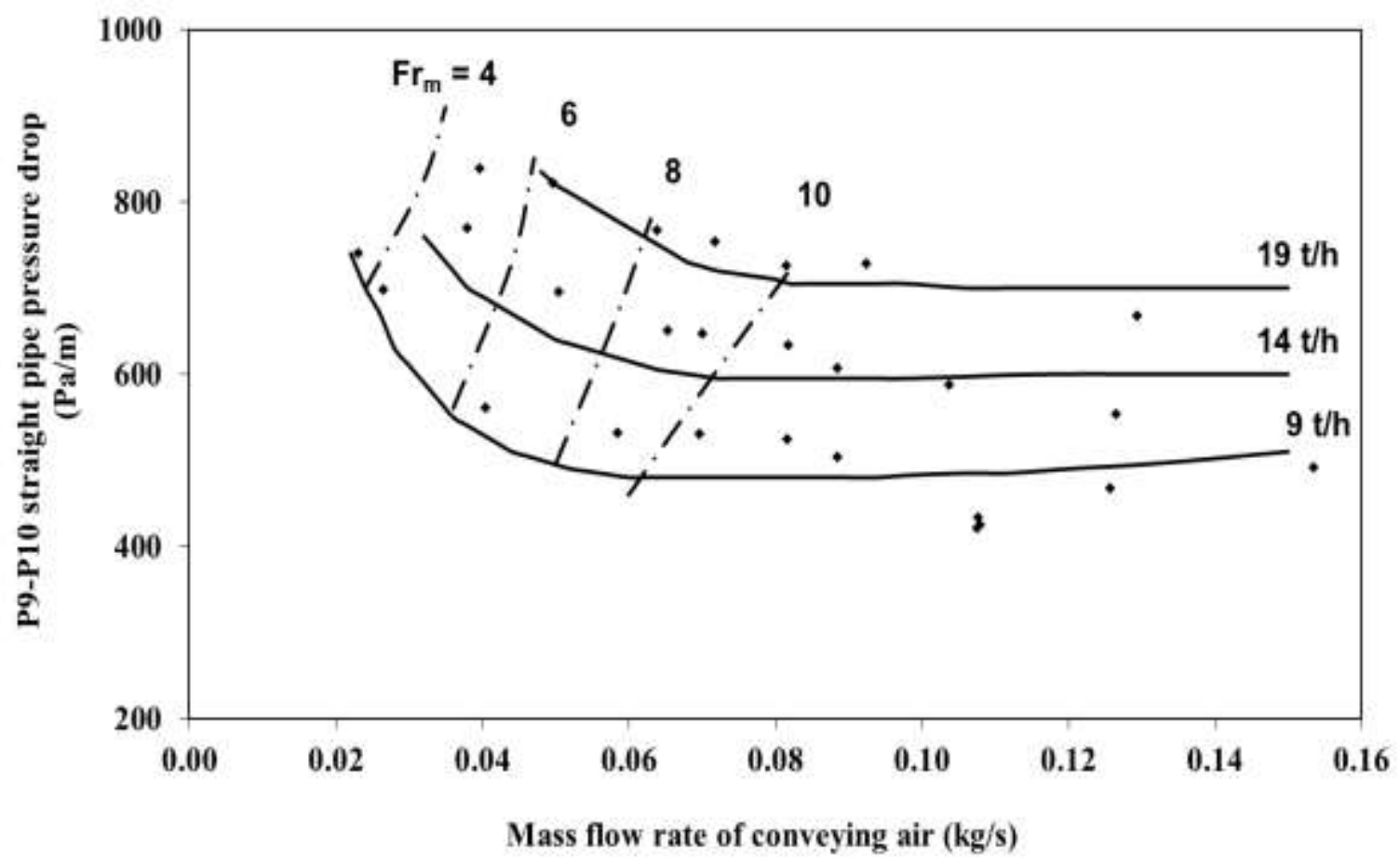

Figure 2: Straight-pipe Pneumatic Conveying Characteristics (PCC) for fly ash, P9-P10, $69 \mathrm{~mm}$ I.D. $\times 168 \mathrm{~m}$ long pipe. 


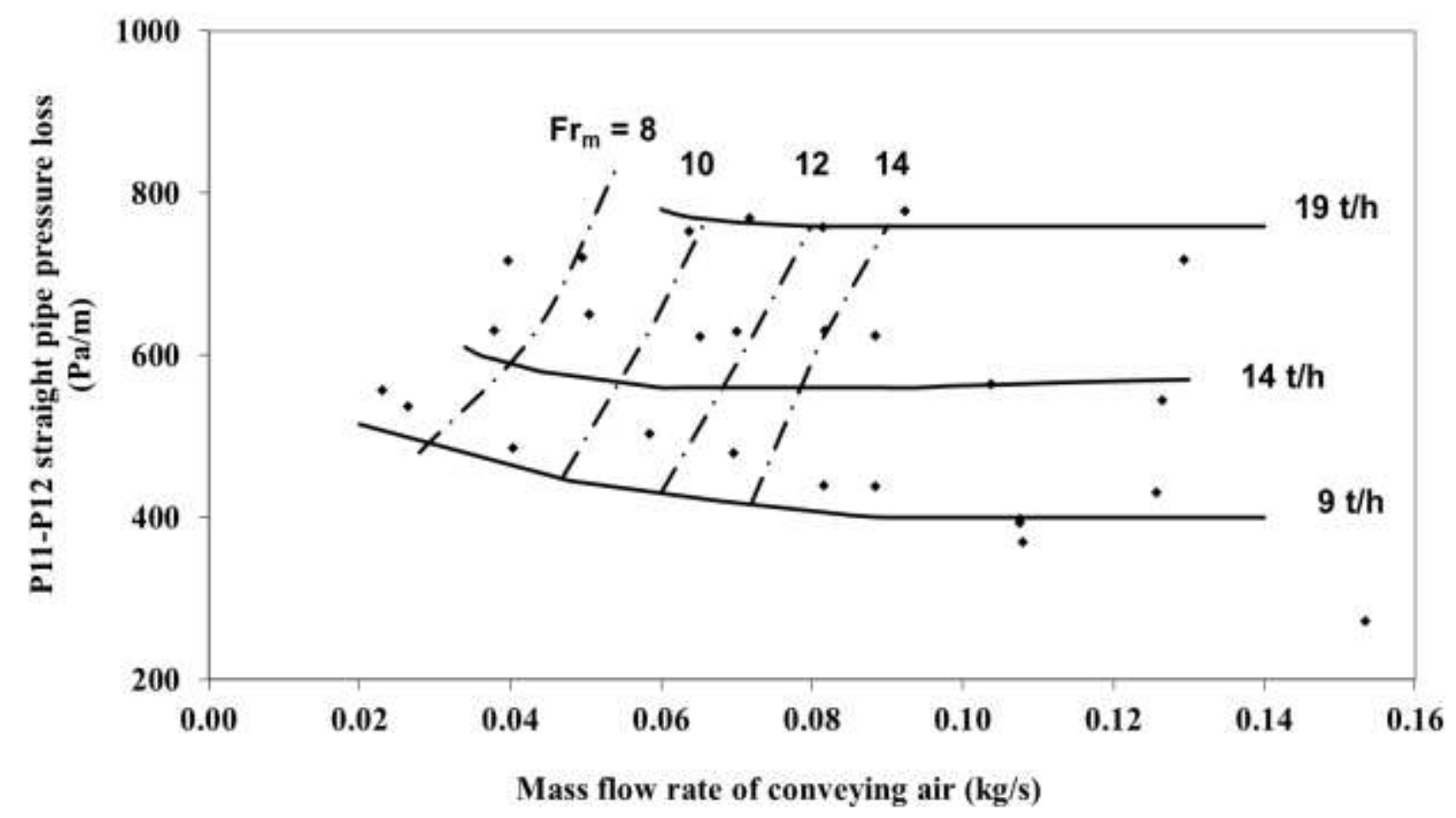

Figure 3: Straight-pipe Pneumatic Conveying Characteristics (PCC) for fly ash, P11-P12, $69 \mathrm{~mm}$ I.D. $\times 168 \mathrm{~m}$ long pipe.

Comparing Figures 2 and 3, it becomes evident that the PCC for "straight pipe" sections (even for the same product, i.e. fly ash) differ depending upon the location of the tapping points, thus indicating a change in local flow mechanisms. For $m_{a}=0.082 \mathrm{~kg} / \mathrm{s}, m_{s}=14.2 \mathrm{t} / \mathrm{h}$, mean velocity of within P9-P10 is calculated as $9 \mathrm{~m} / \mathrm{s}$, whereas for the same values of $m_{a}$ and $m_{s}$ (same experiment), mean velocity within P11-P12 is calculated as $11.2 \mathrm{~m} / \mathrm{s}$. The PCC obtained from the initial section of the pipe loop (i.e. P9-P10) show a significant portion where pressure drop decreases with an increase in air flow rate. On the other hand, the PCC obtained from the latter section of the pipe loops (i.e. P11-P12) show a more significant flat portion (i.e. pressure drop 
remains almost constant with increasing air flow rate). This indicates a possible change in flow characteristics along the pipeline.

\section{Flow model for solids-gas transport}

Considering the following assumptions, the governing equations for the flow have been developed:

- One-dimensional flow along the bulk flow direction (x-direction).

- In an infinitesimal control volume, the gas-solids composition is uniform with no concentration gradient of particles across the diameter of pipe.

- The gas-solids flow is in steady state.

- Ideal gas equation of state is obeyed by gas-phase in an isothermal system.

Considering mass, momentum and energy balance across a small control volume [22], the following governing equations have been obtained: 


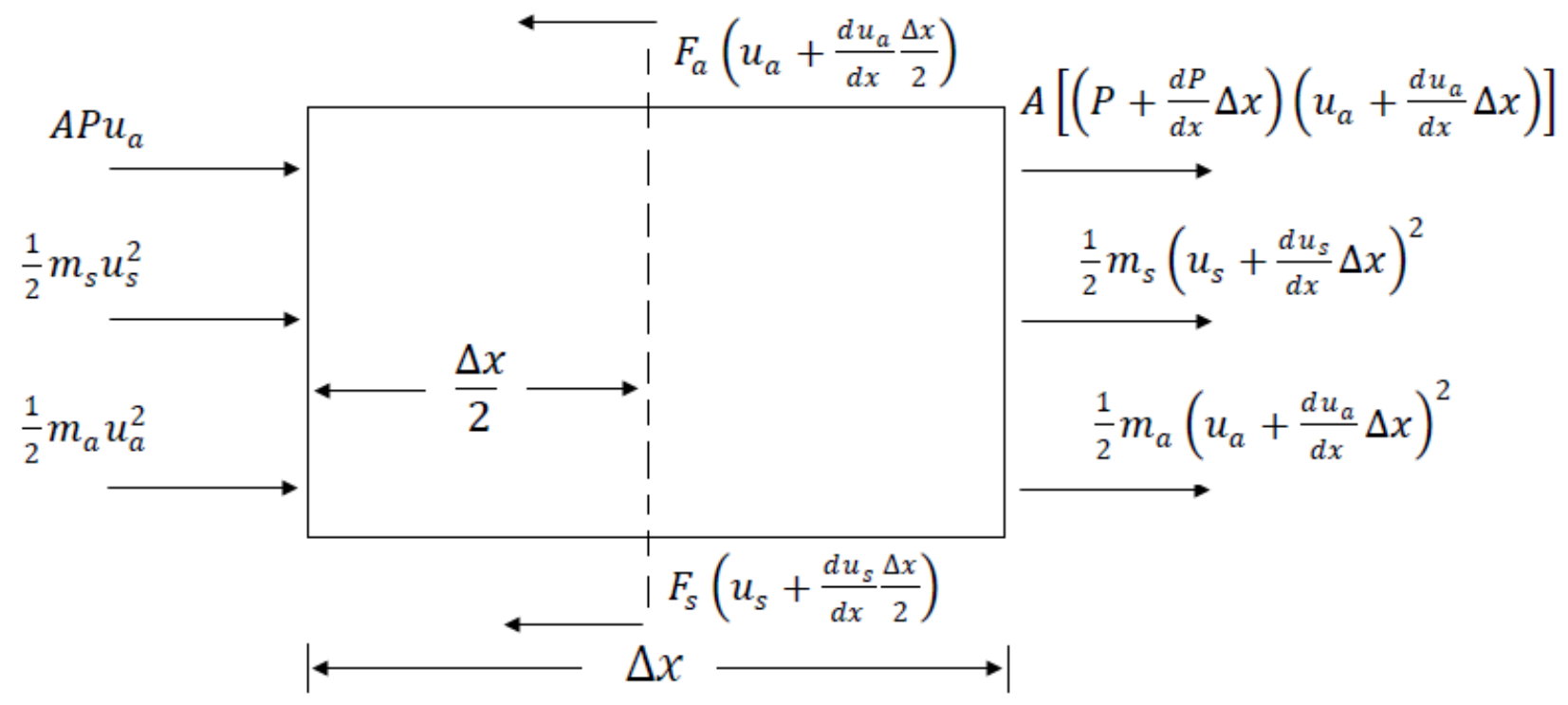

Figure 4: Energy exchanges across a control volume

Along x-direction, considering the velocities of air and solids phase as well as their respective frictional forces, pressure and area of cross-section of the pipeline, net accumulation of momentum is:

$=A P u_{a}-A\left[\left(P+\frac{d P}{d x} \Delta x\right)\left(u_{a}+\frac{d u_{a}}{d x} \Delta x\right)\right]-\left[F_{a}\left(u_{a}+\frac{d u_{a}}{d x} \frac{\Delta x}{2}\right)+F_{s}\left(u_{s}+\frac{d u_{s}}{d x} \frac{\Delta x}{2}\right)\right]$

To study the nature of gas-solids flow dynamics, Kuang et al. studied the resultant energy dissipation generated from the inter-particles, particles and wall, particles and fluid, and between fluid to fluid interactions [23]. Computational analysis has been performed using CFD-DEM based technique to solve the following equations:

$$
\begin{aligned}
& m_{i} \frac{d v_{i}}{d t}=f_{p g f, i}+f_{d r a g, i}+\sum_{j=1}^{k_{i}}\left(f_{c, i j}+f_{d, i j}\right)+m_{i} g \\
& I_{i} \frac{d \omega_{i}}{d t}=\sum_{j=1}^{k_{i}}\left(T_{t, i j}+T_{r, i j}\right)
\end{aligned}
$$


$\frac{\partial\left(\rho_{f} \varepsilon_{f}\right)}{\partial t}+\nabla \cdot\left(\rho_{f} \varepsilon_{f} u\right)=0$

$\frac{\partial\left(\rho_{f} \varepsilon_{f} u\right)}{\partial t}+\nabla \cdot\left(\rho_{f} \varepsilon_{f} u u\right)=-\nabla P-F_{p-f}+\nabla \cdot\left(\varepsilon_{f} \tau\right)+\left(\rho_{f} \varepsilon_{f}\right) g$

Equations (2) and (3) correspond to particle or solids flow, and equations (4) and (5) correspond to gas flow. However, the results concluded that dissipation in energy occurred due to particlefluid interaction, particle-wall friction and fluid-wall viscous energy at steady state pneumatic conveying. In an inclined flow, gravitational potential energy generates an additional energy loss in such systems. In view of the results presented in [23], the net accumulation of kinetic energy along $\mathrm{x}$-direction is given by:

$$
=\frac{1}{2} m_{a} u_{a}^{2}+\frac{1}{2} m_{s} u_{s}^{2}-\frac{1}{2} m_{a}\left(u_{a}+\frac{d u_{a}}{d x} \Delta x\right)^{2}-\frac{1}{2} m_{s}\left(u_{s}+\frac{d u_{s}}{d x} \Delta x\right)^{2}
$$

Assuming, at steady state there is no net accumulation of energy in the control volume and neglecting the higher order terms, we get:

$P \frac{d u_{a}}{d x}+u_{a} \frac{d P}{d x}+u_{a} f_{a}+u_{s} f_{s}+\rho_{a} \varepsilon_{a} u_{a}^{2} \frac{d u_{a}}{d x}+\rho_{s} \varepsilon_{s} u_{s}^{2} \frac{d u_{s}}{d x}=0$

For gas-solids flow, the conservation of momentum is written as:

$$
\begin{aligned}
& {\left[\left(\rho_{a} \varepsilon_{a} A u_{a}\right)\left(u_{a}+\frac{d u_{a}}{d x} \Delta x\right)-\left(\rho_{a} \varepsilon_{a} A u_{a}\right) u_{a}\right]+\left[\left(\rho_{f l} \varepsilon_{s} A u_{s}\right)\left(u_{s}+\frac{d u_{s}}{d x} \Delta x\right)-\left(\rho_{f l} \varepsilon_{s} A u_{s}\right) u_{s}\right]} \\
& \quad=\left[P A-\left(P+\frac{d P}{d x} \Delta x\right) A\right]-F_{a}-F_{s}
\end{aligned}
$$

Dividing both sides of equation (8) by elemental volume $(A \Delta x)$,

$\varepsilon_{a} \rho_{a} u_{a} \frac{d u_{a}}{d x}+\varepsilon_{s} \rho_{f l} u_{s} \frac{d u_{S}}{d x}+\frac{d P}{d x}=-f_{a}-f_{s}$ 
Mass conservation for gas-phase and solids-phase are given by the following equations, respectively:

$\frac{d}{d x}\left(\varepsilon_{a} \rho_{a} u_{a}\right)=0$

$\frac{d}{d x}\left(\varepsilon_{s} \rho_{f l} u_{s}\right)=0$

Gas-phase and solids-phase are related by the following relation:

$\varepsilon_{a}+\varepsilon_{s}=1$

Following equations represent the evolution of parameters $u_{s}, u_{a}, \varepsilon_{s}$ and $P$ w.r.t the pipleline distance $x$ and are known as evolution equations of the system. These equations show how the different parameters under the study are varying with the evolving flow.

$\frac{d u_{s}}{d x}=\frac{u_{s}}{\varepsilon_{s}\left(\rho_{f l} u_{s}^{2}\left(u_{s}-u_{a}\right)-\frac{u_{a} P}{\left(1-\varepsilon_{s}\right)}\right)}\left[-\left(u_{s}-u_{a}\right) f_{s}+\frac{u_{a} P}{\rho_{a}} \frac{d \rho_{a}}{d x}\right]$

$\frac{d u_{a}}{d x}=-\frac{u_{a}}{\rho_{a}} \frac{d \rho_{a}}{d x}-\frac{u_{a}}{\left(1-\varepsilon_{s}\right)\left(\rho_{f l} u_{s}^{2}\left(u_{s}-u_{a}\right)-\frac{u_{a} P}{\left(1-\varepsilon_{s}\right)}\right)}\left[-\left(u_{s}-u_{a}\right) f_{s}+\frac{u_{a} P}{\rho_{a}} \frac{d \rho_{a}}{d x}\right]$

$\frac{d \varepsilon_{s}}{d x}=-\frac{1}{\left(\rho_{f l} u_{s}^{2}\left(u_{s}-u_{a}\right)-\frac{u_{a} P}{\left(1-\varepsilon_{S}\right)}\right)}\left[-\left(u_{s}-u_{a}\right) f_{s}+\frac{u_{a} P}{\rho_{a}} \frac{d \rho_{a}}{d x}\right]$

$\frac{d P}{d x}=-f_{a}-f_{s}+\left(1-\varepsilon_{s}\right) u_{a}^{2} \frac{d \rho_{a}}{d x}+\frac{\left(\rho_{a} u_{a}^{2}-\rho_{f l} u_{s}^{2}\right)}{\left(\rho_{f l} u_{s}^{2}\left(u_{s}-u_{a}\right)-\frac{u_{a} P}{\left(1-\varepsilon_{s}\right)}\right)}\left[-\left(u_{s}-u_{a}\right) f_{s}+\frac{u_{a} P}{\rho_{a}} \frac{d \rho_{a}}{d x}\right]$ 
Coupled first order differential equations (13) to (16) are explicitly dependent on the air and solids phase velocity, volume fraction of solids, pressure, rate of change of air density, and friction force per unit volume due to air and solids phase. To obtain solutions of the $u_{s}, u_{a}$, $\varepsilon_{s}$ and $P$ equations (13) to (16) have been solved numerically. The numerical procedure to solve the equations along the pipeline length is being discussed. The entire horizontal pipeline length has been divided into a number of different sections consisting of straight pipe sections and bends. The segments of the pipeline has been marked at following distant points starting from the origin or the inlet of the pipe: $3.26 \mathrm{~m}, 24.62 \mathrm{~m}, 60.84 \mathrm{~m}, 81.31 \mathrm{~m}, 98.78 \mathrm{~m}$ and $129 \mathrm{~m}$ (Figure 1). A set of coupled ordinary differential equations (equations (13) to (16)) have been solved section by section with numerical technique based on the fourth-fifth-order Runge-Kutta-Fehlberg (RKF45) method $[24,25]$. The values used for parameters $f_{s}, f_{a}, \rho_{a}$ and $\frac{d \rho_{a}}{d x}$ have been obtained from the experiments conducted through $69 \mathrm{~mm}$ I.D. x $168 \mathrm{~m}$ long test rig. It is assumed that the well aerated mixture of solid particles occupy the full cross-section of the pipeline when the product is discharged from the blow tank. Subsequently, the occupancy of solid particles decreases along the direction of flow. Following relation has been used to obtain the initial condition for particle velocity:

$u_{s}=\frac{m_{s}}{A \rho_{f l}}$

The initial values for the succeeding section are the numerical values obtained from the exit point of the preceding section. This practice has been followed throughout the pipeline till the exit point. System parameters, i.e. $u_{s}, u_{a}, \varepsilon_{s}, u_{s} / u_{a}$ and $P$, are calculated at each small interval of the pipeline section. Fluidized bulk density for this fly ash was experimentally determined as $300 \mathrm{~kg} / \mathrm{m}^{3}$ [22]. 


\section{Stability Analysis}

Stability analysis is an important aspect of studying a system to identify its feasible operational zone during the installation of new system or implying modifications to the existing design of the system. Stability analysis considering linearization, Taylor's series expansion and Lyapunov analysis have been discussed in details for gas-solids flow mechanism [1]. In the present investigation, the linearization approach has been adopted to study the stability of the system. The linearized equations, thus obtained, have been used to find the associated eigenvalues. Actual gas and solids velocity, volume fraction of solids and pressure have been studied through eigenvalue and phase space analysis. In order to proceed with the stability analysis of the system, it is necessary to linearize the nonlinear evolution equations (13) to (16).

$$
\begin{aligned}
& \frac{d u_{s}}{d x}=A_{11} u_{s}+A_{12} u_{a}+A_{13} \varepsilon_{s}+A_{14} P \\
& \frac{d u_{a}}{d x}=A_{21} u_{s}+A_{22} u_{a}+A_{23} \varepsilon_{s}+A_{24} P \\
& \frac{d \varepsilon_{s}}{d x}=A_{31} u_{s}+A_{32} u_{a}+A_{33} \varepsilon_{s}+A_{34} P \\
& \frac{d P}{d x}=A_{41} u_{s}+A_{42} u_{a}+A_{43} \varepsilon_{s}+A_{44} P
\end{aligned}
$$

Equations (18) to (21) are the linearized form of evolution equations (13) to (16). From linearized equations (18) to (21), the following Jacobi determinant can be constructed from the derivatives w.r.t solids velocity, actual air velocity, volume fraction for solids and pressure at an equilibrium state. 


$$
\left|\begin{array}{cccc}
A_{11}-\lambda & A_{12} & A_{13} & A_{14} \\
A_{21} & A_{22}-\lambda & A_{23} & A_{24} \\
A_{31} & A_{32} & A_{33}-\lambda & A_{34} \\
A_{41} & A_{42} & A_{43} & A_{44}-\lambda
\end{array}\right|=0
$$

where, $\lambda$ is the eigenvalue of the Jacobi determinant. The steady state solutions of the linearized evolution equations are stable, if the coefficients of the resultant eigenvalue equation assume positive real values. The resultant eigenvalue in its general form can be represented as:

$\lambda^{4}+c_{1} \lambda^{3}+c_{2} \lambda^{2}+c_{3} \lambda+c_{4}=0$

where, the coefficients $c_{i}$ 's (where $i=1$ to 4 ) are the functions of $A_{k l}$ 's (where, $k, l=1$ to 4 ). The solutions of eigenvalue equation (23) provide the information about the stability, quasistability and instability of the system at an equilibrium state. The system is stable if the real part of its eigenvalue solution is a negative real number, and is unstable if the real part of the eigenvalue solution is positive [26]. For this system, the eigenvalues obtained are the combination of negative and positive real numbers, thus indicating that the system behaves like saddle point, it is neither stable nor unstable. The phase portraits obtained converge in every case under study, thus demonstrating that the system is operating under the stable conditions. However, on the contrary, it is indicating that the dunes formed at the initial point of the pipe (blow tank discharge) are deforming gradually as the flow moves towards the exit point of the pipeline. As the gas-solids flow develops along the pipeline, the solids and actual gas velocity increases and the pressure drops down with the reduction in volume fraction of solids [22]. The flow changes from fluidizeddense to dilute-phase. To determine the stability behavior of the system near equilibrium, the 
associated phase portraits demonstrate the system behavior very intricately. Phase portraits of gas and solids velocity are shown Figure 5.

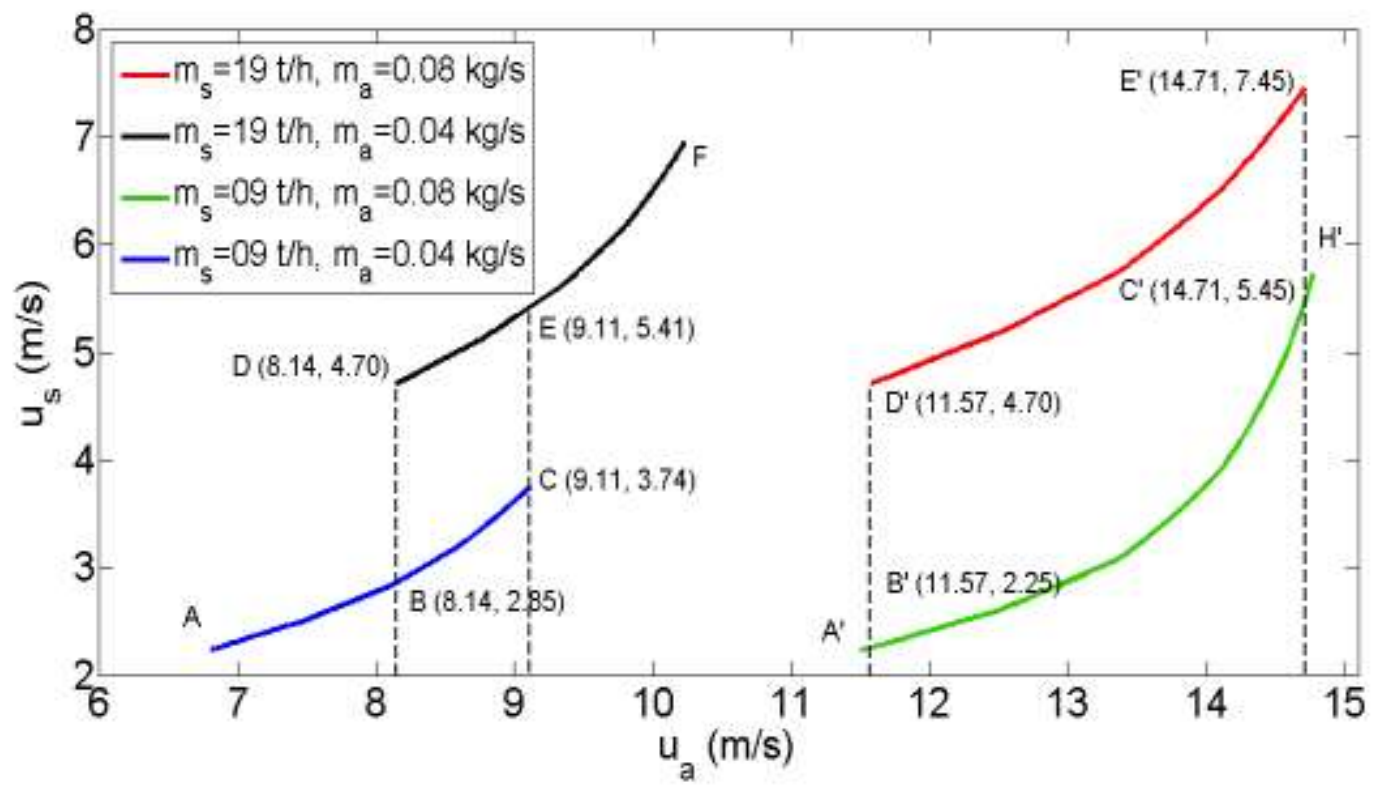

Figure 5: Change in particle velocity with increasing actual gas velocity along the pipeline.

Figure 5 shows that the velocity of gas and solids increase as the flow develops. The rate of increase of particle velocity is steeper as compared to that of gas velocity. This analytical study has been conducted for the certain operating conditions with four different combination of mass flow rates of solids and gas, i.e., $m_{s}=19 t / \mathrm{h}$ and $m_{a}=0.08 \mathrm{~kg} / \mathrm{s} ; m_{s}=19 \mathrm{t} / \mathrm{h}$ and $m_{a}=$ $0.04 \mathrm{~kg} / \mathrm{s} ; m_{s}=09 \mathrm{t} / \mathrm{h}$ and $m_{a}=0.08 \mathrm{~kg} / \mathrm{s} ;$ and $m_{s}=9 t / \mathrm{h}$ and $m_{a}=0.04 \mathrm{~kg} / \mathrm{s}$. In every plot (Figures 5 to 10 ), the red line corresponds to $m_{s}=19 t / \mathrm{h}$ and $m_{a}=0.08 \mathrm{~kg} / \mathrm{s}$; black line corresponds to $m_{s}=19 \mathrm{t} / \mathrm{h}$ and $m_{a}=0.04 \mathrm{~kg} / \mathrm{s} ;$ green line corresponds to $m_{s}=9 t / h$ and $m_{a}=0.08 \mathrm{~kg} / \mathrm{s}$ and blue line corresponds to $m_{s}=9 t / \mathrm{h}$ and $m_{a}=0.04 \mathrm{~kg} / \mathrm{s}$. Multiple steady states can be predicted under certain operating conditions. A representation of such condition has 
been shown in Figure 5. The overlapping region of two different mass flow rates, the region between the pairs of dashed lines ( $D B$ and $E C$; $D^{\prime} B^{\prime}$ and $\left.E^{\prime} C^{\prime}\right)$ defines the bi-stability for the different combination of mass flow rate of solids under the same mass flow rate conditions for air. As the range of operating steady state characteristics for mass flow rates of the air increases, the corresponding overlapping region defining the multi-stability tends to shrink. In the velocity phase portrait (Figure 5), as the flow evolves from point $\mathrm{A}$ to $\mathrm{C}$, there is no operation zone for the corresponding mass flow rate of solids $\left(m_{s}=9 t / h\right)$ beyond point $\mathrm{C}$. On increasing the air velocity, there is a step-wise rise to the higher mass flow rate of solids at point $\mathrm{E}\left(m_{s}=19 t / h\right)$ from point $\mathrm{C}\left(m_{s}=9 t / h\right)$. Such sudden change is referred to as bifurcation instability. However, as we move from point $\mathrm{F}$ to $\mathrm{D}$, the system will follow the path $\mathrm{F}$ to $\mathrm{E}$ to $\mathrm{D}$, until the critical point $\mathrm{D}\left(m_{s}=19 t / h\right)$ is reached, the system will undergo a step drop, therefore, falling to point B at lower mass flow rate of solids $\left(m_{s}=9 t / h\right)$. Therefore, it can be inferred that for higher solid flow rate (i.e., $\left.m_{s}=19 t / h\right)$, larger particle velocity $\left(\mathrm{u}_{\mathrm{s}}=4.7 \mathrm{~m} / \mathrm{s}\right)$ would be required to make the flow to start compared to lower solids flow rate (i.e., corresponding to $m_{s}=9 t / h$ ). 


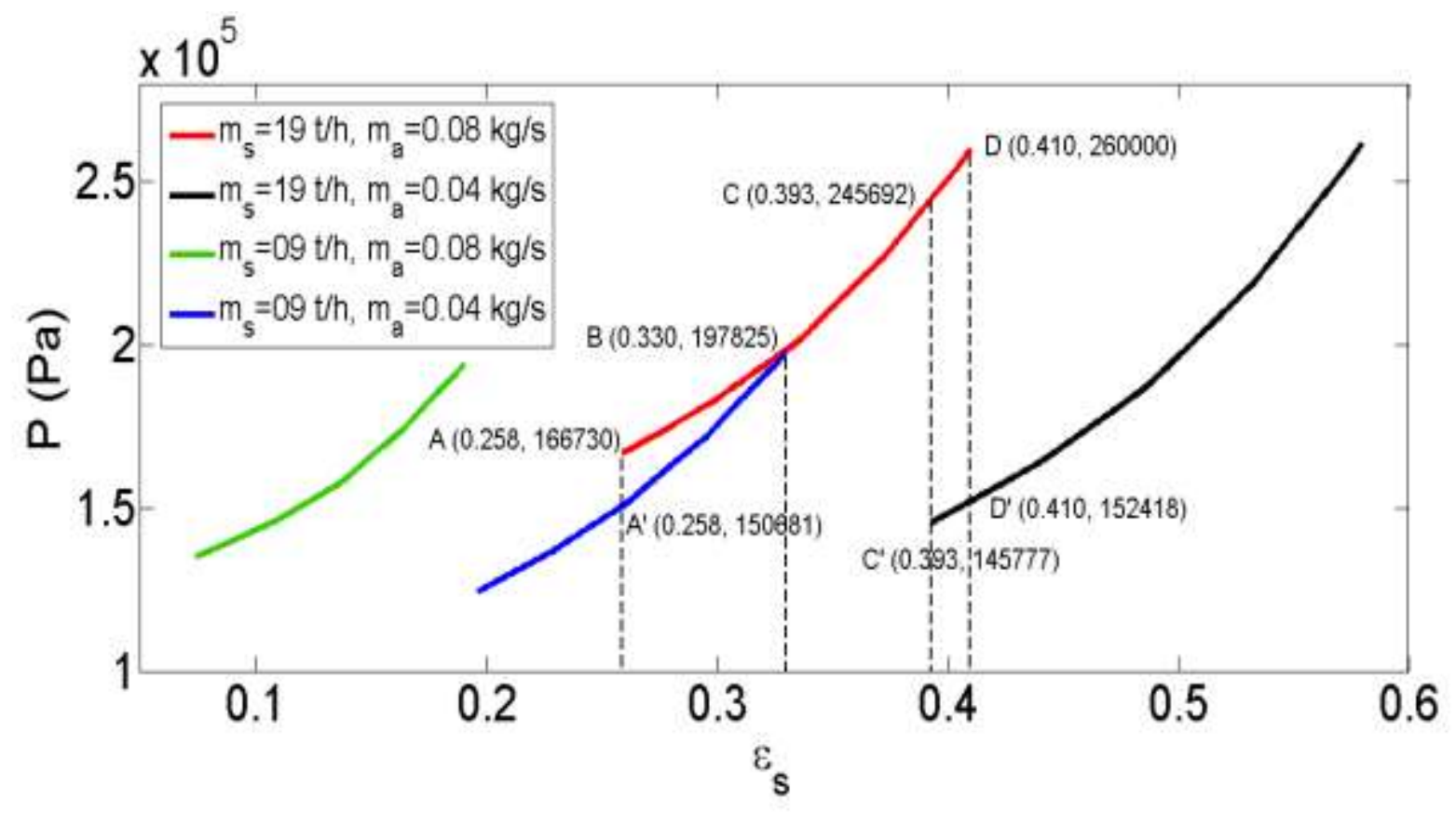

Figure 6: Change in pressure with increasing solids volumetric fraction

Figure 6 shows the trends of change in pressure with an increase in solids volume fraction. As the flow develops along the pipeline, the gas expands in the pipe at steady rate, thus continuously decreasing the pressure along the pipeline length. It is very much obvious that the solids particle concentration decreases as the flow evolves due to the expansion of gas, thus a fluidized-dense phase flow gradually proceeds towards a dilute-phase regime. As a result, the pressure and volume fraction of solids drop as the gas-solids flow develop (Figure 6). On the other hand, volume fraction for gas increases along the direction of flow. As the flow evolves, the gas expands in the pipeline creating the drop in the corresponding pressure value. In the test rig schematic (Figure 1), there are closely coupled bends after $80 \mathrm{~m}$ of pipeline length, which are responsible for the steep rise in the trends of solids to gas velocity ratio, as the solids particles de-accelerates due to bends and change in direction of motion. This can be due to the drop in the gas pressure as it flows through the closely coupled bends and the accompanying effect of gas expansion. Bistable operational 
states have been observed for the region under the curve $A B$ and $C D$ in the air velocity versus pressure plot (Figure 7). The system exhibits multiple steady states for different combinations of the mass flow rates of solids and gas. In solids velocity versus pressure plot, the region under the curve $E F$ shows the multiple operational states for the system (Figure 8). However, in figure 8, the area under the curves $\mathrm{AB}$ and FG shows the bi-stable zones. The multi-stable states under the curve $E F$ in Figure 8 are considerably important as the transition between the different mass flow rates of air and solids has been observed.

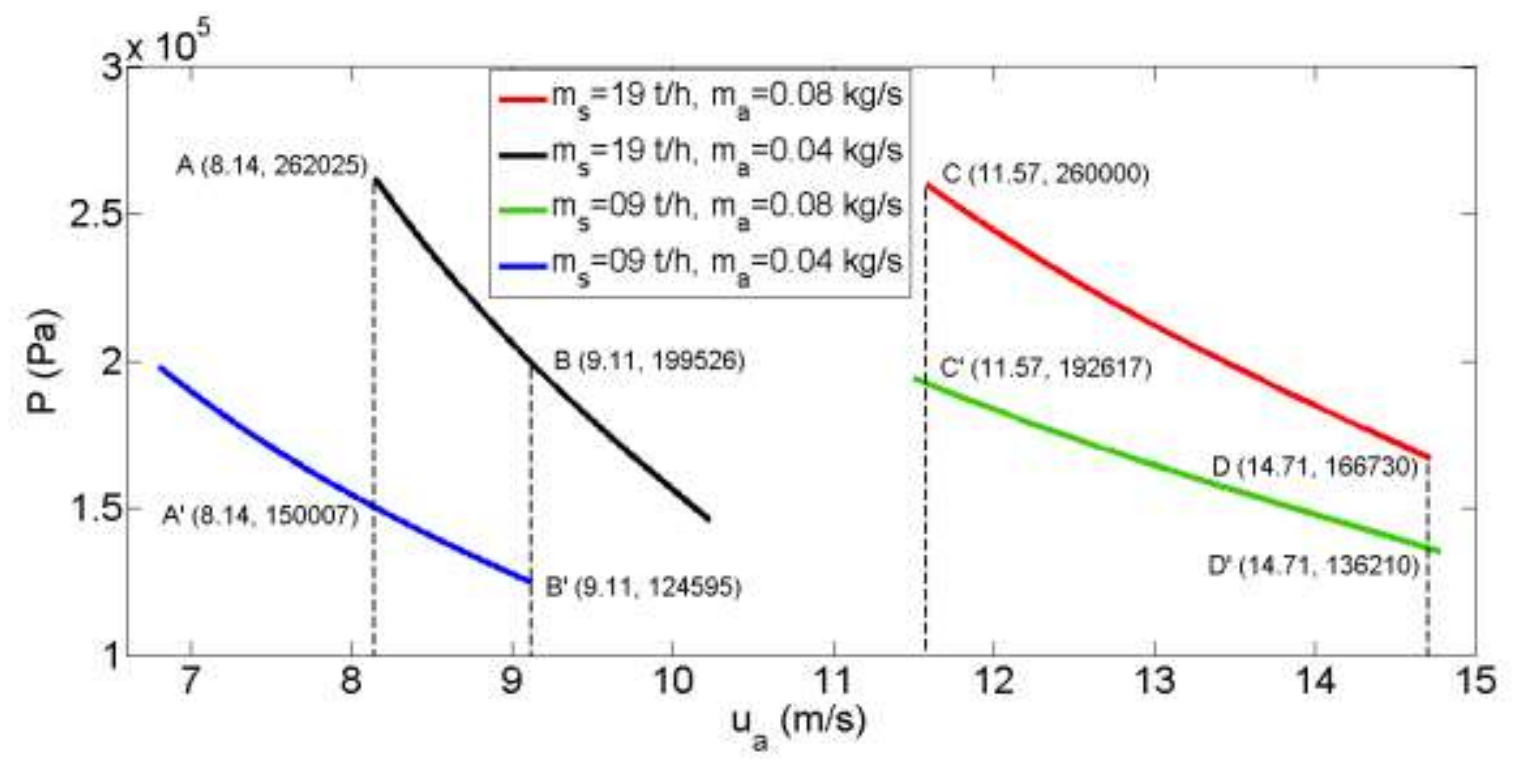

Figure 7: Change in pressure with increasing actual air velocity. 


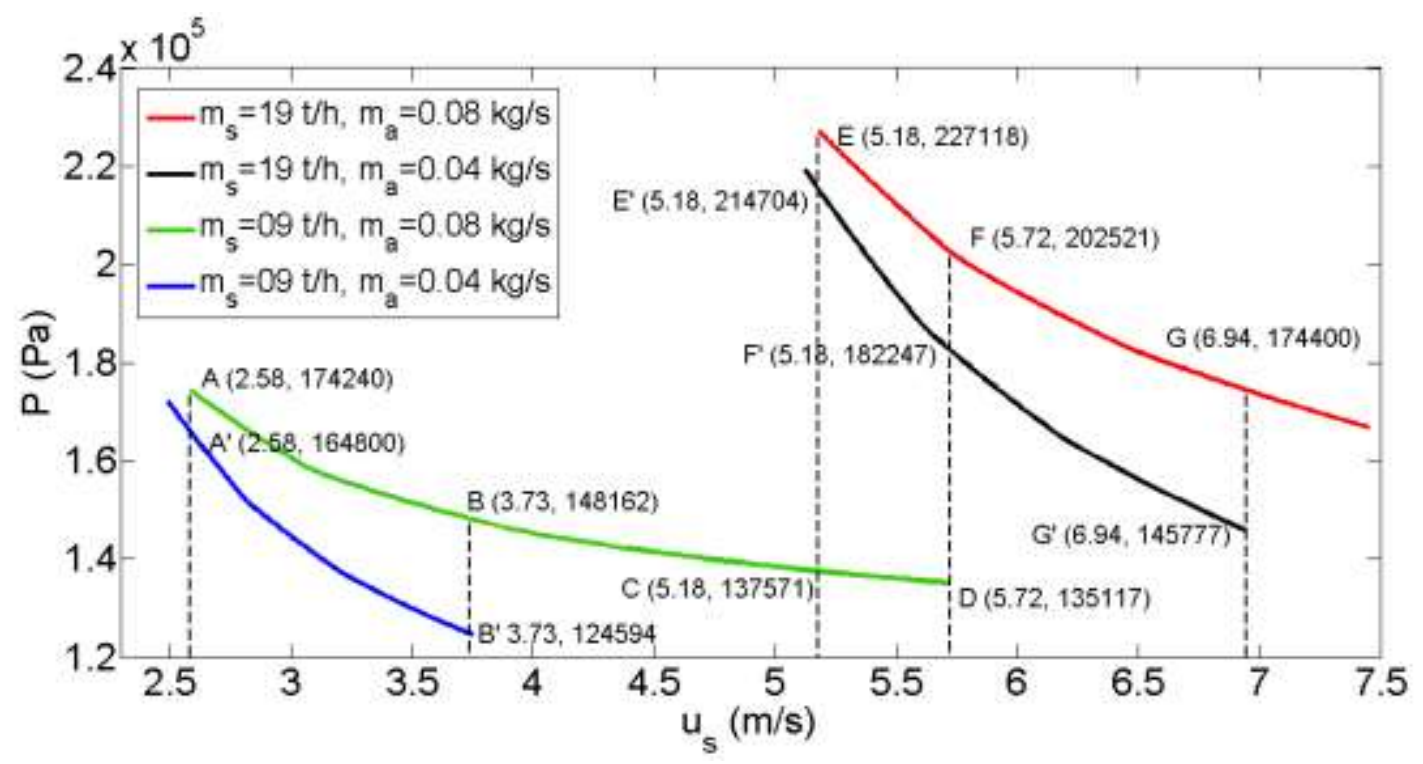

Figure 8: Change in pressure with increasing particle velocity.

Figure 9 show the 3-dimensional representation of pressure drop versus actual air velocity and particle velocity. As can be comprehended from the Figure 9, corresponding to the different combinations of $u_{s}$ and $u_{a}$, pressure drop can be determined for each combination of the flow rates. Increase in the air and solids velocity results in the pressure drop in the system along the pipeline. Rate of pressure drop is significantly higher corresponding to the lower values of mass flow rate of air. Figure 9 gives the comprehensive trend of variation in pressure with change in velocities of gas and solids phase. In this plot, the variation of pressure can be predicted due to the change in both gas and solids phase velocities. 


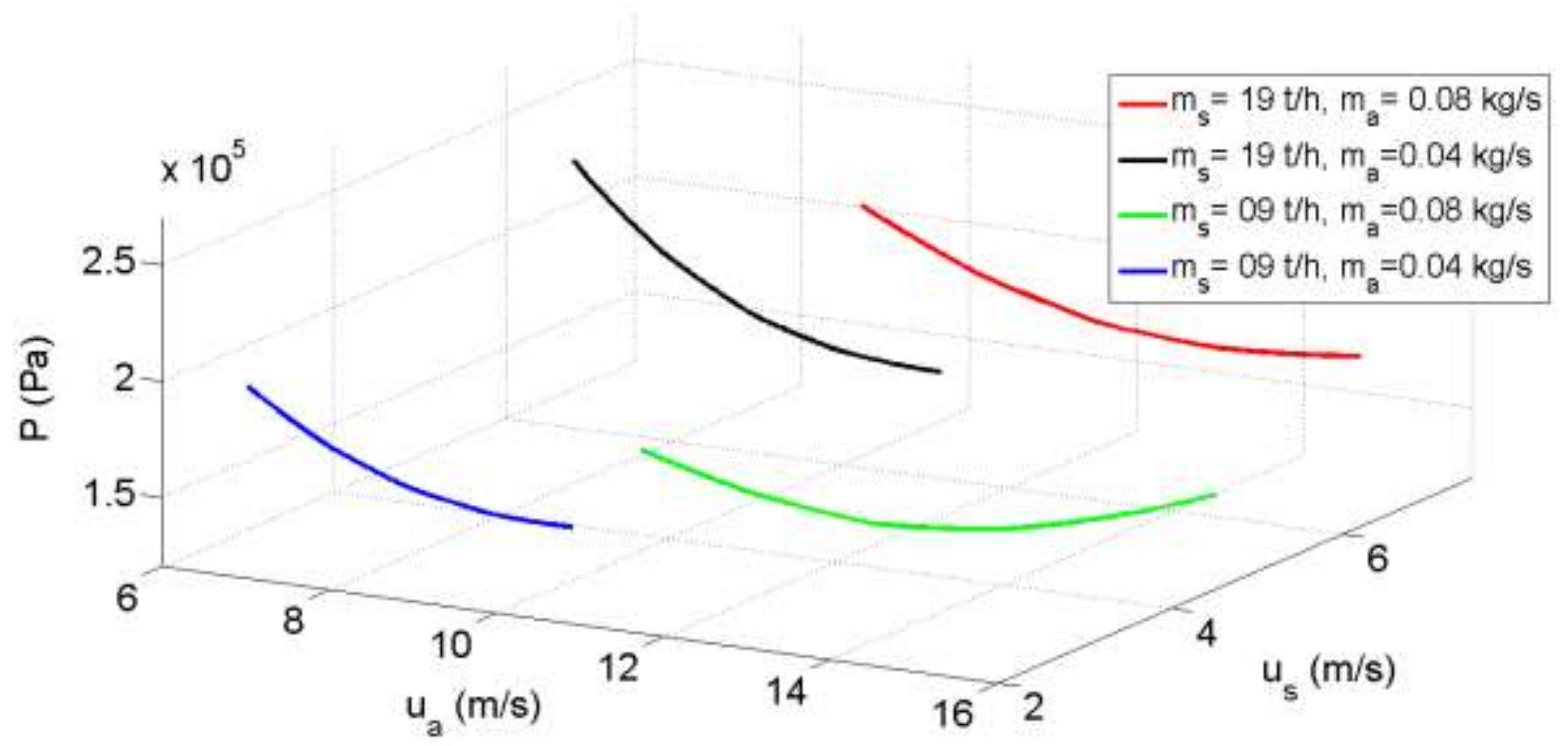

Figure 9: Change in pressure with increasing particle velocity and actual air velocity.

Figure 10 shows the 2-dimensional representation of solids friction factor versus particle velocity and actual air velocity plots. Solid lines represent the variation of solids friction factor with respect to gas velocity $\left(u_{a}\right)$, while the dash-dot lines represent the variation with respect to solids velocity $\left(u_{s}\right)$. 


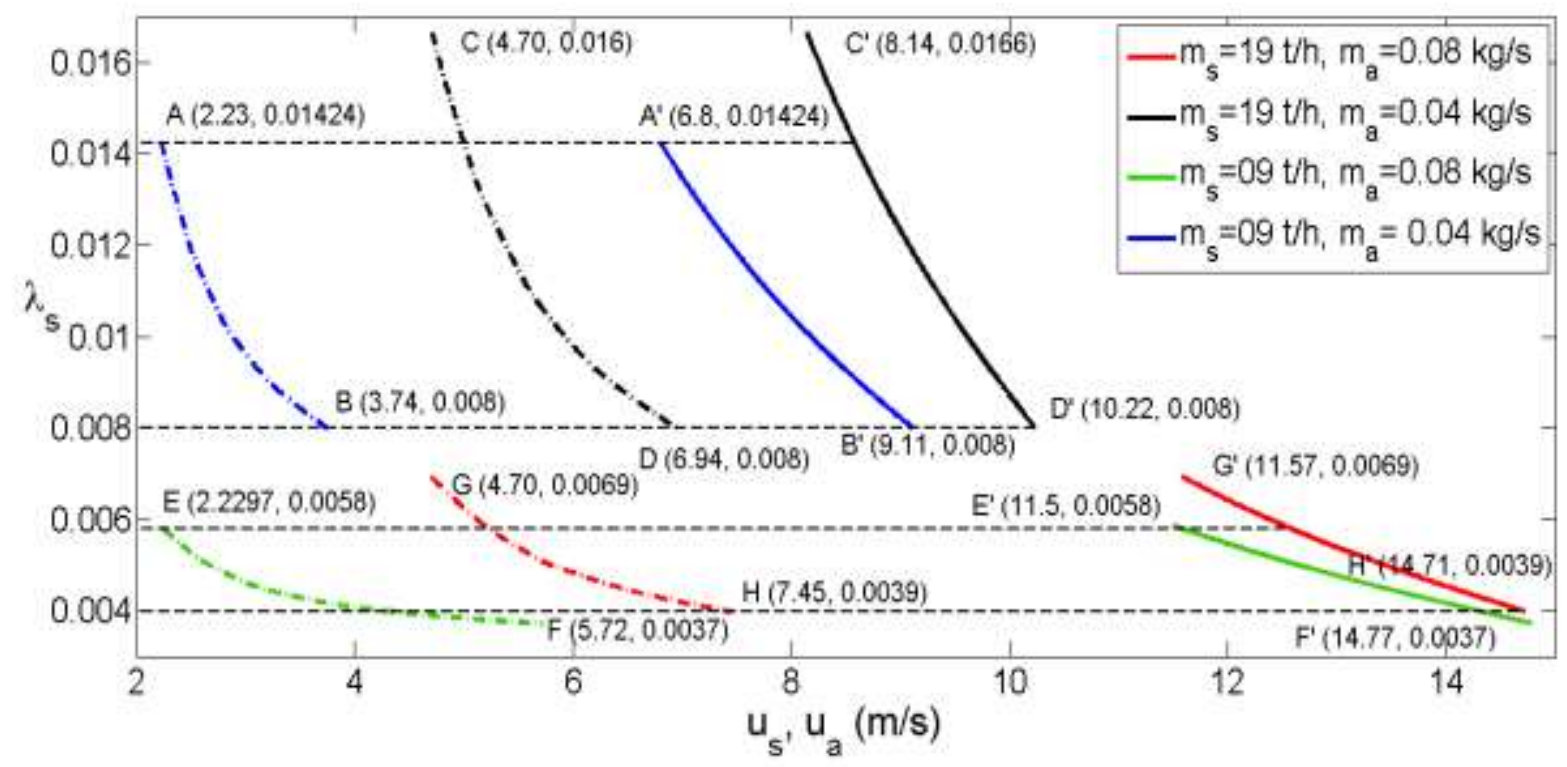

Figure 10: Variation of solids velocity (dash-dot lines) and gas velocity (solid lines) with respect to solids friction factor.

It can be observed in the above figure that there are different combinations of $u_{s}$ and $u_{a}$ which could lead to the same value of solid friction factor, e.g. $\lambda_{\mathrm{s}}=0.01424$ can be achieved corresponding to $u_{s}=2.23 \mathrm{~m} / \mathrm{s}$ and $u_{a}=6.8 \mathrm{~m} / \mathrm{s}$ as well as for $u_{s}=5.0 \mathrm{~m} / \mathrm{s}$ and $u_{a}=$ $8.3 \mathrm{~m} / \mathrm{s}$. Similarly, $\lambda_{s}=0.008$ can be achieved corresponding to $u_{s}$ and $u_{a}$ combinations of $3.74 \mathrm{~m} / \mathrm{s}$ and $9.11 \mathrm{~m} / \mathrm{s}$ as well as $6.94 \mathrm{~m} / \mathrm{s}$ and $10.22 \mathrm{~m} / \mathrm{s}$. In Figure 10, it has been observed that the range of solids friction factor is larger for the lower mass flow rate of air as compared to the higher mass flow rates of air. The solids friction factor is more dominant in lower air flow rates. It is also important to mention that the solids friction factor decreases more steeply for lower mass flow rates of air with increasing air and solids velocities, whereas, for higher mass flow rates of air the system experiences gradual decrease in solids friction factor. Higher values of mass flow rate of solids experience faster rate of drop in solids friction factor than its lower counterpart. The 
results in this paper would be helpful in understanding and choosing the suitable flow rate conditions in the pneumatic conveying systems. This study can be extended to the different samples and with much larger range of mass flow rates of solids and air.

\section{Conclusion}

The flow dynamics of gas-solids flow and stability of four critical conveying parameters: pressure drop, particle and solids velocities, and solid volume fraction has been studied for fly ash samples. The possible change in the characteristics of dunes and transport mechanisms in the direction of flow has been validated by the change in slopes of straight-pipes pneumatic conveying characteristics along the length of pipe. Two- and three-dimensional phase space portraits with different combinations of conveying parameters show that as the flow develops, solids and actual air velocities increase, solids volume fraction decreases (along the direction of flow) and pipeline pressure drops. The solids friction factor has decreased with the increasing actual gas and solids velocities. Multi-stable operating zones for the sample of fly ash has been predicted at certain mass flow rate of air and solids. The behavior of solids friction factor for the fly ash samples has been studied as the flow develops in the pneumatic conveying system. Lower mass flow rates of air experience the steeper fall in the solids friction factor which is more dominant in such systems.

\section{List of symbols and abbreviations}

\begin{tabular}{|l|l|}
\hline$A$ & Cross sectional area of control volume $\left[\mathrm{m}^{2}\right]$ \\
\hline$A_{11}, A_{12}, A_{21}, A_{22}, A_{33}, A_{44}$ & Coefficients of linearized evolution equations $[1 / \mathrm{m}]$ \\
\hline
\end{tabular}




\begin{tabular}{|c|c|}
\hline$A_{13}, A_{23}$ & Coefficients of linearized evolution equations [1/s] \\
\hline$A_{14}, A_{24}$ & Coefficients of linearized evolution equations $[\mathrm{ms} / \mathrm{kg}]$ \\
\hline$A_{31}, A_{32}$ & Coefficients of linearized evolution equations $\left[\mathrm{s} / \mathrm{m}^{2}\right]$ \\
\hline$A_{34}$ & Coefficients of linearized evolution equations $\left[\mathrm{s}^{2} / \mathrm{kg}\right]$ \\
\hline$A_{41}, A_{42}$ & Coefficients of linearized evolution equations $\left[\mathrm{kg} /\left(\mathrm{m}^{3} \mathrm{~s}\right)\right]$ \\
\hline$A_{43}$ & Coefficients of linearized evolution equations $[\mathrm{Pa} / \mathrm{m}]$ \\
\hline$c_{1}$ & Coefficient of eigenvalue equation $[1 / \mathrm{m}]$ \\
\hline$c_{2}$ & Coefficient of eigenvalue equation $\left[1 / \mathrm{m}^{2}\right]$ \\
\hline$c_{3}$ & Coefficient of eigenvalue equation $\left[1 / \mathrm{m}^{3}\right]$ \\
\hline$c_{4}$ & Coefficient of eigenvalue equation $\left[1 / \mathrm{m}^{4}\right]$ \\
\hline$d_{p}$ & Particle diameter $[\mu \mathrm{m}]$ \\
\hline$d_{50}$ & Median particle diameter $[\mu \mathrm{m}]$ \\
\hline$F r=V /(g D)^{0.5}$ & Froude number of flow \\
\hline$F_{a}$ & Frictional force due to air phase $[\mathrm{N}]$ \\
\hline$F_{S}$ & Frictional force due to solids phase $[\mathrm{N}]$ \\
\hline$F_{p-f}$ & Volumetric force between particles and fluids $\left[\mathrm{N} / \mathrm{m}^{3}\right]$ \\
\hline$f_{a}$ & Frictional force per unit volume due to air phase $\left[\mathrm{N} / \mathrm{m}^{3}\right]$ \\
\hline$f_{s}$ & Frictional force per unit volume due to solids phase $\left[\mathrm{N} / \mathrm{m}^{3}\right]$ \\
\hline$f_{c, i j}$ & Contact force between $\mathrm{i}^{\text {th }}$ and $\mathrm{j}^{\text {th }}$ particles $[\mathrm{N}]$ \\
\hline$f_{d, i j}$ & Damping force between $\mathrm{i}^{\text {th }}$ and $\mathrm{j}^{\text {th }}$ particles $[\mathrm{N}]$ \\
\hline$f_{p g f, i}$ & Pressure gradient force on $\mathrm{i}^{\text {th }}$ particle $[\mathrm{N}]$ \\
\hline$g$ & Acceleration due to gravity $\left[\mathrm{m} / \mathrm{s}^{2}\right]$ \\
\hline
\end{tabular}




\begin{tabular}{|c|c|}
\hline$I_{i}$ & Particle moment of inertia of $\mathrm{i}^{\text {th }}$ particle $\left[\mathrm{kg} \mathrm{m}^{2}\right]$ \\
\hline$L$ & Length of horizontal pipe or test section [m] \\
\hline$L_{v}$ & Length of vertical pipe or test section $[\mathrm{m}]$ \\
\hline$m_{f}, m_{a}$ & Mass flow rate of air $[\mathrm{kg} / \mathrm{s}]$ \\
\hline$m_{s}$ & Mass flow rate of solids $[\mathrm{kg} / \mathrm{s}]$ \\
\hline$m_{i}$ & Mass of the $i^{\text {th }}$ particle $[\mathrm{kg}]$ \\
\hline$m^{*}=m_{s} / m_{a}$ & Solids loading ratio \\
\hline$P$ & Pressure $[\mathrm{Pa}]$ \\
\hline$T_{t, i j}$ & Tangential component of the torque between $\mathrm{i}^{\text {th }}$ and $\mathrm{j}^{\text {th }}$ particles $[\mathrm{N} \mathrm{m}]$ \\
\hline$T_{r, i j}$ & Rolling friction torque between $\mathrm{i}^{\text {th }}$ and $\mathrm{j}^{\text {th }}$ particles $[\mathrm{N} \mathrm{m}]$ \\
\hline$u_{a}$ & Actual gas velocity $[\mathrm{m} / \mathrm{s}]$ \\
\hline$u_{s}$ & Particle or dune velocity $[\mathrm{m} / \mathrm{s}]$ \\
\hline$u$ & Gas velocity $[\mathrm{m} / \mathrm{s}]$ \\
\hline$v_{i}$ & Translational velocity of $\mathrm{i}^{\text {th }}$ particle $[\mathrm{m} / \mathrm{s}]$ \\
\hline \multicolumn{2}{|l|}{ Greek symbols } \\
\hline$\rho, \rho_{a}, \rho_{f}$ & Density of air $\left[\mathrm{kg} / \mathrm{m}^{3}\right]$ \\
\hline$\rho_{s}$ & Particle density $\left[\mathrm{kg} / \mathrm{m}^{3}\right]$ \\
\hline$\rho_{b}$ & Loose-poured bulk density $\left[\mathrm{kg} / \mathrm{m}^{3}\right]$ \\
\hline$\rho_{f l}$ & Fluidized bulk density $\left[\mathrm{kg} / \mathrm{m}^{3}\right]$ \\
\hline$\lambda$ & Eigenvalue $[1 / \mathrm{m}]$ \\
\hline$\lambda_{f}$ & Air/gas only friction factor \\
\hline$\lambda_{s}$ & Solids friction factor through straight pipe \\
\hline
\end{tabular}




\begin{tabular}{|l|l|}
\hline$\varepsilon_{f}, \varepsilon_{a}=V_{a} /\left(V_{a}+V_{s}\right)$ & Volume fraction of air \\
\hline$\varepsilon_{s}=V_{s} /\left(V_{a}+V_{s}\right)$ & Volume fraction of solids \\
\hline$\tau$ & Fluid viscous stress tensor $\left[\mathrm{kg} /\left(\mathrm{m} \mathrm{s}^{2}\right)\right]$ \\
\hline$\omega_{i}$ & Angular velocity of $\mathrm{i}^{\text {th }}$ particle $\left[\mathrm{s}^{-1}\right]$ \\
\hline & \\
\hline Abbreviations & \\
\hline CFD & Computational Fluid Dynamics \\
\hline DEM & Discrete Element Model \\
\hline PCC & Pneumatic conveying characteristics \\
\hline I.D. & International diameter \\
\hline
\end{tabular}




\section{References}

[1] G.E. Klinzing, R.D. Marcus, F. Rizk and L.S. Leung, Pneumatic Conveying of Solids - A Theoretical and Practical Approach, Chapman \& Hall, 1997.

[2] S.S. Mallick, PhD Dissertation, Modelling dense-phase pneumatic conveying of powders, University of Wollongong, 2009.

[3] R. Pan, Material properties and flow modes in pneumatic conveying, Powder Technology, 104(2) (1999) 157-163.

[4] B. Mi and P.W. Wypych, Investigations into wall pressure during slug-flow pneumatic conveying, Powder Technology, 84 (1995) 91-98.

[5] P.W. Wypych, O.C. Kennedy and P.C. Arnold, The future potential of pneumatically conveying coal through pipelines, Bulk Solids Handling, 10 (1990) 421-427.

[6] R. Pan, P.W. Wypych, Scale up procedures for pneumatic conveying design, Powder Handling and Processing 4 (2) (1992) 167-172.

[7] M.G. Jones, K.C.Williams, Solids friction factors for fluidized dense phase conveying, Particulate Science and Technology, 21 (2003) 45-56.

[8] G. Setia, S.S. Mallick, P.W. Wypych, On Improving Solid Friction Factor Modelling for Fluidized Dense-Phase Pneumatic Conveying Systems, Powder Technology 257 (2014) 88-103.

[9] G. Setia, S.S. Mallick, P.W. Wypych and R. Pan, Modeling solids friction factor for fluidized dense-phase pneumatic transport of powders using two layer flow theory, Powder Technology, 294 (2016) 80-92. 
[10] N. Behera, V. K. Agarwal, M.G. Jones and K. Kenneth C. Williams, Modeling and analysis for fluidized dense phase conveying of powders, Particulate Science and Technology, 31 (2013) 136-146.

[11] H K Khalil, Nonlinear Systems, third edition, Prentice Hall, USA, 2002.

[12] C. Narayanan, Linear stability analysis of particle- aden mixing layers, Internal Report, LKT-01-01, Nuclear Engineering Laboratory, ETHZurich, Switzerland, 2001.

[13] D. Puzyrev, S. Yanchuk, A.G. Vladimirov and S.V. Gurevich, SIAM J. Appl. Dyn. Syst. 13 (2014), 986-1009.

[14] J.G. Charney, R. Fjørtoft, J. von Neumann, Numerical Integration of the Barotropic Vorticity Equation, Tellus, 2 (1950) 237-254.

[15] Y.M. Chen, S. Rangachari, and R. Jackson, Theoretical and Experimental Investigation of Fluid and Particle Flow in a Vertical Standpipe, Ind. Eng. Chem. Fundam., 23 (1984) 354370.

[16] C. Narayanan, D. Lakehal, and G. Yadigaroglu, Linear stability analysis of particle-laden mixing layers using Lagrangian particle tracking, Powder Tech., 125 (2002) 122- 130.

[17] O. Owoyemi and P. Lettieri, Stability analysis and CFD validation of a new fluid-particle interaction force for mono-component gas-solid fluidized beds, Powder Tech. 183 (2008) $27-36$.

[18] P. Eshuis, K. van der Weele, M. Alam, H.J. van Gerner, M. van der Hoef, H. Kuipers, S. Luding, D. van der Meer, D. Lohse, Buoyancy driven convection in vertically shaken granular matter: experiment, numerics, and theory, Granular Matter 15 (2013) 893-911.

[19] K. Mandich and R.J. Cattolica, Stability of an Inclined, Pneumatically-Transported System of Particles, AIChE J., 62 (2016) 2248-2258. 
[20] C. Zhang, Q. Wang, Z. Jia, U. Muhammad, W. Qian, and F. Wei, Design of parallel cyclones based on stability analysis, AIChE J., 62 (2016) 4251-4258.

[21] W.D. Fullmer and C.M. Hrenya, The Clustering Instability in Rapid Granular and GasSolid Flows, Annu. Rev. Fluid Mech., 49 (2017) 485-510.

[22] B. Kaur, A. Mittal, P. Wypych, S.S. Mallick and S. Jana, On Developing Improved Modelling and Scale-up Procedures for Pneumatic Conveying of Fine Powders, Powder Technology, 305 (2017) 270-278.

[23] S. B. Kuang, R. P. Zou, R. H. Pan, A. B. Yu, Gas solid flow and energy dissipation in inclined pneumatic conveying, Industrial \& Engineering Chemistry Research, 51 (2012) 14289-302.

[24] E. Fehlberg, Low-order classical Runge-Kutta formulas with step size control and their application to some heat transfer problems, NASA Technical Report, 315 (1969).

[25] L. Shampine, H. Watts and S. Davenport, Solving Non-stiff ordinary differential equations - the state of the art, SIAM Review, 18 (1976) 376-411.

[26] S. Strogatz, Nonlinear Dynamics and Chaos, second edition, Westview press, USA, 2014. 